\title{
Cystatin C to Creatinine Ratio Measurement
}

National Cancer Institute

\section{Source}

National Cancer Institute. Cystatin C to Creatinine Ratio Measurement. NCI Thesaurus.

Code C106513.

The determination of the ratio of cystatin C compared to creatinine present in a sample.

The measurement may be expressed as a ratio or percentage. 